\title{
Family Physician Scope of Practice: What It Is and Why It Matters
}

\author{
Warren P. Newton, MD, MPH
}

The two American Board of Family MedicineRobert Graham Center policy briefs in this issue of the Fournal of the American Board of Family Medicine mark the beginning of an American Board of Family Medicine (ABFM) initiative to define and track the scope of practice of family physicians. In keeping with its commitment to the health of the public, the ABFM has launched a strategic initiative to evaluate the impact and effectiveness of Maintenance of Certification and to publish the results, no matter what they are, in the peer-reviewed literature. As a part of this initiative, we now begin to report what we know about the scope of practice of board-certified family physicians. We believe that what family physicians do is fundamental to both the health of the public and the discipline of family medicine.

Key to considering the scope of practice of family physicians is the question of just what are we doing right now and how this varies by region and by physician characteristics such as age cohort and sex. Given the large numbers of family physicians across the United States and the large variation in practice across regions, tracking trends is very difficult. Information routinely collected by the ABFM can make a major contribution. Since the Board was founded, family physicians applying for certification and recertification have completed a short demographic questionnaire when they regis-

Submitted 6 September 2011; revised 6 September 2011; accepted 6 September 2011.

From the American Board of Family Medicine, Lexington, $\mathrm{KY}$.

Funding: none.

Conflict of interest: none declared.

Corresponding author: Warren Newton, MD, MPH, UNC Department of Family Medicine, CB \#7595 William Aycock Bldg., Chapel Hill, NC 27599-7595. (E-mail: Warren_Newton@med.unc.edu).

\section{See Related Article on Pages 635} and 637. tered. These demographic questions have included information about scope of practice as well as other characteristics of the practice. Given that applicants must fill out the demographic page, and given that the large majority of family physicians go through recertification, these data represent an approximately $1 / 7$ sample of the population of board-certified family physicians in the United States. It should be underscored that this is not a perfect random sample of family physicians - not all physicians have been on an exact 7-year cycle, and there remains an approximately $15 \%$ of family physicians who are unable to or choose not to become board certified. ${ }^{1}$ Despite this caveat, however, Board demographic surveys represent the best available data for tracking the scope of practice of family physicians over time.

The first policy brief ${ }^{2}$ reports data from the component of the demographic survey in which physicians estimate what percentage of their clinical time is spent in various aspects of practice. For a given physician, if any time was mentioned, it was analyzed as if that component was a part of their scope of practice. The brief thus reports that many family physicians do not spend time on preoperative or postoperative care (80\% to $90 \%$ ) or maternity care $(85 \%)$. This is not surprising. What is surprising, however, is the number of family physicians who report no time spent on office surgery (almost 60\%), psychiatry $(>55 \%)$, or pediatrics $(>25 \%)$.

What do these data mean? Clearly, they should be understood as being preliminary. How family physicians interpret these areas of practice and how accurately physicians estimate time spent on various components of practice is debatable. But these results are consistent from year to year and the approach to analysis-if physicians reported any time, it was included as representing that element of the scope of practice-should protect against underestimates of breadth of scope of practice. If these results are confirmed on closer examination, however, they are of great importance for our dis- 
cipline. Major questions immediately follow: How do they vary by region? by rurality? by phase of career? The major premise of our founding and our residency educational system is comprehensiveness of care. We would like to think that family physicians will be able to take care of almost whatever walks in the door.

The other policy brief underscores the link between scope of practice and reimbursement. ${ }^{3}$ As is well known, the Patient Protection and Affordable Care Act mandated a (temporary) $10 \%$ payment increase for primary care for Medicare patients. The question faced by Medicare was how to define the group of primary care providers who would qualify for increased reimbursement. Having claims easily available, the Center for Medicare and Medicaid Services proposed to define primary care providers as those who submitted more than half of their claims using evaluation and management $(\mathrm{E} \& \mathrm{M})$ claims. The brief demonstrates that the proposed rule actually discriminated against family physicians practicing in rural areas. Approximately one sixth of the American population lives in rural areas, and the proportion of family physicians in a given area increases with increasing rurality. Indeed, it is the comprehensiveness of care provided by rural family physicians that is critical to the care of rural communities. As in the first brief, it would be good to know more methodologic details such as how preventive services codes were addressed. This also illustrates the importance of focused, databased advocacy, which caused the Center for Medicare and Medicaid Services to change their rule and increase capture of family physicians from $50 \%$ to $80 \%$. Ultimately, of course, reimbursement of family physicians ought to recognize the value of services like telephone management or coordination of care; however, in the meantime, insurers will continue to find it very convenient to consider only fee-for-service claims.

It is important to underscore that distribution of codes is also relevant when fees are being reduced. As state budgets go sour, a number of states have cut Medicaid reimbursement for physicians. In some states, Medicaid leaders have tried to protect primary care. An example comes from the North Carolina, which cut fees differentially for different kinds of providers, emphasizing cuts in procedure codes over E\&M codes. As with increases in payments, there is a dilemma of both overinclusion and underinclusion. Many non-primary care providers use E\&M codes, and many primary care providers, particularly family physicians working in rural and underserved areas, include procedures as a major part of their practice. To assume that E\&M codes are used only by primary care providers unintentionally raises the fees of limited care specialists. Conversely, to cut procedural codes selectively has a disproportionate impact on family physicians who need a broader scope of practice to care for their patients. Interestingly, in North Carolina, there was an additional option for the Medicaid program: to give increased payments to the practices that patients choose as their medical home. This choice allows payment (and analytics) to be organized around practices and individual providers. This use of patient choice is one of the important foundations of the Community Care of North Carolina program: it is often the medical home practices rather than individual providers that are the functional units of care that provide access, comprehensive care, and coordination.

These briefs (and others in coming months) use historic data from the ABFM demographic page. We believe they are an important contribution to knowledge about the current scope of practice of family physicians. At the same time, however, the Maintenance of Certification framework will allow more frequent sampling of physicians. We are also working to standardize the questions about scope and context of practice. The new demographic survey will begin in 2012 .

Our hope is to engage the discipline in a dialogue about scope of practice. We believe that the promise of Family Medicine to the public depends in part on our comprehensiveness of practice. What we do-and where and for how long we do it-matters. A first step is refining our ability to find out what we are doing now.

\section{References}

1. Xierali IM, Rinaldo JC, Green LA, et al. Family physician participation in maintenance of certification. Ann Fam Med 2011;9:203-10.

2. Bazemore AW, Petterson S, Johnson N, et al. What services do family physicians provide in a time of primary care transition? J Am Board Fam Med 2011; 24:635-6.

3. Petterson S, Bazmore AW, Phillips RL, et al. Rewarding family medicine, while penalizing comprehensiveness? Primary care payment incentives and health reform: the Patient Protection and Affordable Care Act (PPACA). J Am Board Fam Med 2011;24:637-8. 